Часть 3. Команды высшей миги

В.Шульцева, старший научный сотрудник ИМЭМО РАН / vshul@imemo.ru

УДК 338.24, DOI: 10.22184/2070-8963.2019.84.7.72.78

Эпоха доминирования Запада в области hi-tech-кооперации меняет свой традиционный облик. "Фабрика Азия" стремительно наращивает масштабы и качественный уровень потоков товаров и услуг. Западные корпорации не отступают, удерживая превосходство в инновационности торгуемых продуктов, от их зарождения до производственного освоения, но знания становятся новым полем брани для государств и компаний.

Чтобы выжить и преуспеть, надо вооружиться самым убийственным из орудий - знанием. K. Нордстем

\section{ПОТАЕННЫЙ ЯРОСТНЫЙ НI-ТЕСН-АЗАРТ ВОСТОКА}

"Азиатский век", о пришествии которого уверенно утверждают политические лидеры континента и подтверждают расчеты аналитиков МВФ, наступит уже в будущем году. Доля региона в мировой ВВП (по ППС) в 2020 году превысит 50\% (20\% в 2000 году). Один из главных факторов такого беспрецедентного подъема, способного стимулировать и формировать будущий этап глобализации, - стремительный рост hi-tech-кооперации в рамках "умных цепочек стоимости". Успешные технологические компании Азии менее чем за 30 лет сумели полностью переформатировать "домашний" уровень производства и поднять планку экономической зрелости в Китае, Австралии, Японии, Новой Зеландии, Сингапуре, Южной Корее до общемировых стандартов. Главный инструментарий подвижников - энергия мысли, сила воли, одержимость победой, стремительное усвоение новых знаний и их адаптация в собственном производстве.

Первый мощный вклад в развитие ГЦДС в АТР сделала страна Восходящего Солнца. Японские компании-производители электроники стремительно ворвались на мировой рынок в 1960-х годах, захватив пальму первенства у американских и европейских компаний. Колосс мирового hi-tech-экспорта возглавил эшелоны регионального офшоринга. 3а лидером не замедлили и продолжают встраиваться экономические тигры региона. И сегодня вся Азия говорит Японии: "Спасибо!".

\section{SONY: ЗВЕЗДА ЭЛЕКТРОННОГО БИЗНЕСА}

Она была в когорте первых энтузиастов международной кооперации. Легендарные ее основатели Акио Морита и Масару Ибука превратили лейбл Made in Japan в эталон качества, синоним надежности и символ новаторства. Благодаря их таланту компания впитала лучшие мировые ценностные практики и обогатила тем самым национальный традиционный колорит своего корпоративного бизнеса, а это было далеко не просто. Япония оказалась поразительно восприимчива к новаторству. Но для взлета экономики из руин второй мировой войны одних инноваций мало. Необходимо было "переформатировать" сакральную национальную доктрину "вакон есай" ("японский дух - западная техника"), то есть максимально использовать новейшие зарубежные изобретения без малейшего ущерба основам японской морали. Важнейшая часть догмата - общинное мышление в корпоративной поведенческой 
практике - в корне противоречила западной концепции. Но блестящий стратег и бизнес-дирижер Акио Морита победил парадокс гармонией. Продукция компании в течение нескольких десятилетий была одной из самых популярных в мире, не менее чем продукция Apple сегодня. Обе - лидеры "персональных технологий". Именно муза Sony дарила вдохновение яблоку, а первый iPOD - озарение звезды Walkman (портативный кассетный плеер Уокмэн) от Sony...

Так как же рождаются великие компании? Акио Морита всегда говорил, что к успеху идут по нехоженым тропам. Рассудительности японских бизнесменов он предпочел динамичный рост, рисковые инновации и стратегии первооткрывателя - "поступать так, как не решились бы другие". Представляется, что история развития Sony заслуживает серьезного изучения для всех команд цифрового ринга.

\section{СТАРТ ИЛИ ЕГО ВЕЛИЧЕСТВО СЛУЧАЙ}

В апреле 1946 года среди развалин послевоенного Токио случайно встретились два физика - 38-летний Масару Ибука и 25-летний Акио Морита, работавшие ранее вместе в японской оборонной промышленности. И ровно через две недели - 7 мая 1946 года на втором этаже полуразрушенного магазина готовой одежды они основали компанию Tokyo Tsushin Kogyo ("Токийская телекоммуникационная инженерная компания"), сокращенно Totsuko, которая позднее была переименована в Sony. Ее команда насчитывала всего 20 человек, а уставной капитал (подарок отца Мориты) - 375 долл. США.

Увлечение электроникой для основателей было смыслом жизни. Деятельность фирмы вначале не была революционной, это было производство вольтметров, жаровен для риса и мелких электроприборов. Для творческого тандема учредителей это был скучный, рутинный бизнес. Но вначале надо было просто выжить. Первые три года прошли в попытках нащупать то изобретение, которое раскрутит компанию. В самые плохие времена Totsuko оставалась без офиса, приходилось продавать свое имущество, чтобы держаться на плаву, но команда все равно не прекращала работать.

Поиски своего технологического тренда увенчались успехом лишь через три года. Детонатором стал американский магнитофон, приобретенный у оккупационных войск. Это был несовершенный образец звукозаписывающего устройства, с проволочным носителем информации. Естественно, отцы-основатели решили его улучшить. Проволока не выдерживала критики, Totsuko решила изобрести фирменную магнитную ленту. Своя лента также была гарантом того, что будущий потребитель станет покупать и магнитофоны, и ленту к нему - следовательно, можно будет заработать дважды. От безысходности вначале ленту делали вручную из целлофана: его нарезали, покрывали разными составами и тестировали. Но материал искажал звук. Тогда ему на смену пришла особая крафтовая бумага. Ее тоже нарезали на полоски и покрывали экспериментальными составами. Но и это было не то. Только когда компания раздобыла пластик и разработала собственную технологию его применения, дело сдвинулось с мертвой точки. А магнитное покрытие ленты сотрудники получали из оксалата железа, который предварительно обжаривали на сковородке! Стоит отметить, что Sony-Таре оказалась настолько хорошего качества, что сама IBM в 1965 году выбрала именно ее для запоминающего устройства в своих компьютерах. Для маленькой компании это был первый настоящий успех.

За лентой последовал магнитофон G-Туре - основа для будущих разработок компании. Образец имел два минуса, которые ставили крест на его будущем. Он был тяжел (35 кг) и дорого стоил (900 долл.). К тому же компания опередила время - рынок сбыта еще не созрел. Положение спас Верховный суд, который купил 20 штук, чтобы заменить недостающих стенографисток. В условиях послевоенной разрухи это, несомненно, был инженерный подвиг. Несмотря на неудачу, Ибука и Морита верили в свое детище и продолжали совершенствовать прибор, параллельно раскручивая рекламу и маркетинг. И уже через два года вышла новая его версия, вес которой составлял 13 кг. Эта модель (Н-Туре) уже нашла покупателей в системе образования, а следующая - Р-Туре за 200 долл. - побила все рекорды продаж. Результат обязан и умному маркетингу: в комплекте с магнитофоном шло бесплатное сервисное обслуживание. Это было весьма важно, магнитофоны тех лет постоянно ломались из-за отсутствия практики пользования. В итоге Totsuko вышла на хороший оборот своих магнитофонов и лент, а спрос стал настолько велик, что пришлось купить завод и открыть конвейерное производство.

\section{ИННОВАЦИОННОЕ ВТОРЖЕНИЕ}

С приходом транзисторов наступает переломный момент в истории компании. В 1953 году Totsuko за 25 тыс. долл. покупает у Western Electric патент на их производство. Иуже в мае 1954 года она выпускает свой первый образец. В активе компании появилась собственная торговая марка. Известно, что транзисторы были разработаны в лабораториях компании Bell, но никому даже не пришло в голову использовать их для 
радиоиндустрии. США рассматривали возможность применения новых компонентов лишь в военной промышленности, Ибука же сконструировал невинное бытовое радио. Дальнейшие события развертывались молниеносно. На следующий же год компания выпускает первый портативный радиоприемник TR-2 (TR-1 назывался малопопулярный американский транзисторный радиоприемник) и тут же - улучшенный его вариант TR-55. Спустя два года первый "карманный" аналог TR-63 был столь успешен, что его появление называли "началом конца американской носимой электроники". Это был продукт мирового уровня и "законодатель мод". Следуя примеру продав цов приемников, продвинутые его покупатели стали носить рубашки с большими карманами. За два года, преимущественно в США, было продано 500 тыс. TR-63. В определенной степени этому поспособствовал и маркетинг. Кражу со склада компании 4 тыс. приемников Морита "на все сто" использовал в рекламных целях, ибо плохой товар воровать не будут!

Радио становится хитом коммерческого успеха. В 1960 году Sony представляет миру первый транзисторный телевизор, а год спустя первый в мире портативный его аналог. Устройство вызвало настоящий фурор среди потребителей, несмотря на высокую стоимость.

Теперь остановить Totsuko было практически невозможно. Со второй половины 50-х у компании было столько запатентованных технологий, что другие японские компании либо использовали ее комплектующие, либо платили роялти. И Морита решил, что пора выходить на мировой рынок. Для этого, пре жде всего, следовало изменить название компании на звонкое, красивое и короткое. Командный мозговой штурм предложил Sony, как результат симбиоза латинского слова sonus (звук), определяющего род деятельности компании, и двух английских слов sunny (солнечный) и sonny (сынок). Одно "n" изъяли "напрочь", ибо sonny по-японски означает "лишиться денег". Так раз и навсегда был озвучен главный тренд деятельности компании - производство продуктов индустрии развлечений (эмоций) высокого качества с изящным дизайном и на острие самых последних достижений прогресса.

В 1958 году на здании токийского офиса Sony засияло название компании - четыре громадные неоновые буквы (каждая весом 262 кг) и двухтонный знак логотипа. Иллюминация обошлась корпорации в 20 млн иен или в 20\% стоимости ее капитала. Но расходы того стоили. В 1960 году компания десантируется в США. Открывается японская корпорация Sony Corporation of America. И уже в 1963 году Sony, первая из иностранных компаний, продает свои акции на Нью-Йоркской фондовой бирже. Этот выпуск собрал 3 млн долл. (на старте акции продавались за 1,75 долл.), но, что еще важнее, он поднял имидж Sony до мирового уровня. Позже Акио Морита скажет, что это был самый счастливый момент в его карьере. Чтобы добиться более прочного положения на новой территории, Морита временно становится американцем и перевозит всю семью в США. Ему было за тридцать, когда он начал учить английский, и вскоре уже свободно мог вести переговоры с западными партнерами. Общительный и остроумный человек без труда был принят деловым миром НьюЙорка. Он старательно изучает особенности американского бизнеса и находит главный недостаток в характере японского бизнеса - отсутствие открытости. Традиционная замкнутость, непроницаемость японской культуры снижали эффективность управленческих решений. Взгляд изнутри на западный бизнес позволил Морите соединить в своей стратегии опыт Востока и Запада, глубинную японскую самозамкнутость и евроамериканскую транспарентность.

Новые продукты от Sony начинают выстреливать с завидной быстротой. Среди первых бестселлеров: первый в мире транзисторный кассетный видеомагнитофон (1963 год); цветной телевизор Trinitron (1968 год) и культовый портативный кассетный аудиоплеер с наушниками Walkman (1979 год). История рождения гаджета - характерный момент из жизни команды тех лет. "Пробегая мимо" отдела звукозаписи, Ибука увидел, какразработчики пытаются "втиснуть" функции записи и стереозвука в карманный объем магнитофона. И тут же решил: "Никакой записи и никаких динамиков - только пара наушников"! Но полной поддержки не встретил. Многие считали, что отсутствие функции записи не принесет рыночного успеха. Однако руководство настояло, и интуиция не подвела. Ведь то была эпоха рок-н-ролла. Молодежь с утра до вечера слушала "Битлз", "Литтл" и Пресли. Взрослое население, отправляясь на отдых, покупало дорогие стереосистемы (большие и тяжелые магнитофоны) для автомобилей. Плеер же умещался в кармане и в комплекте с наушниками позволял слушать музыку на ходу. Бренд родился от слова walk (ходить, гулять). Успех превзошел все ожидания. Walkman разошелся тиражом в 100 млн шт. Морита даже шутил, назвав его "величайшим изобретением" нового слова, которое ... однако, в 1986 году было включено в Оксфордский словарь английского языка.

В 1982 году компания выпускает на рынок первый компакт-диск. Стандартная емкость CD-ROM в 640 Мб была установлена довольно любопытным способом. Согласно специально проведенному мар кетинговому исследованию, стало известно, что 


\section{(CO)) АО ГЛОНАСС}

IX Международный

Конгресс «ЭРА-ГЛОНАСС»

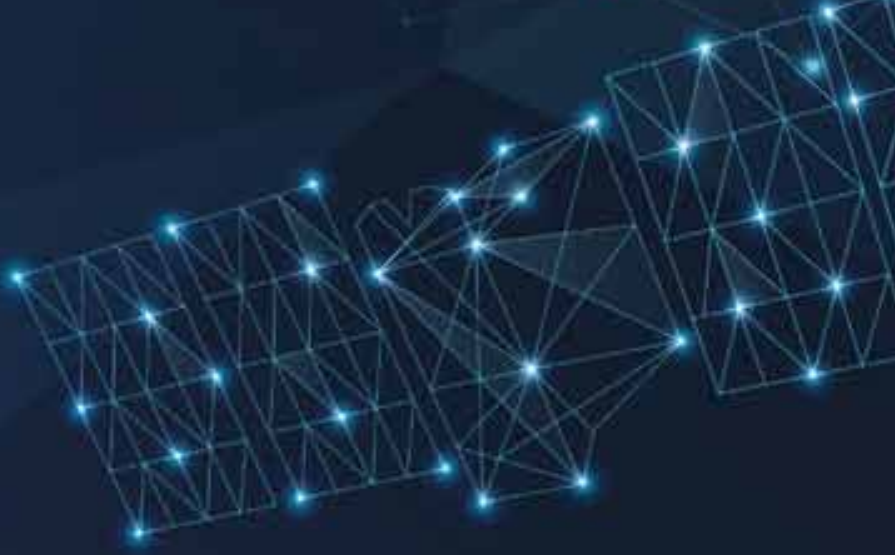

\section{ТЕХНОЛОГИИ ДЛЯ \\ ЧЕЛОВЕКА, БИЗНЕСА, \\ ГОСУДАРСТВА}

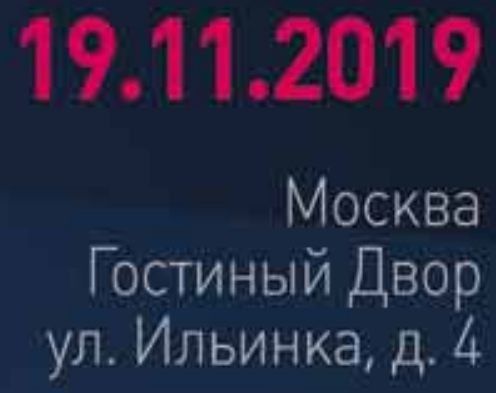

19 ноября 2019 года в Москве в Гостином дворе пройдет IX Международный Конгресс 4ЭРА-ГлоНАCC: технологии для 4еловека, бизнеса, государства.

Мероприятие состоится в рамках ключевого события отрасли-«Транспортной недели $2019 \%$. Opraнизатором Конгресса выступает AO жГЛОНАCC.

Контресс проводится в девятый раз и является одной из хрупнейших дискуссионных площадок в России для обмена опьтом, поиска решений и консолидации усилий в вопросах повышения транспортной безопасности, создания интеллектуальных транспіртных систем, развития информационно-навигационных технологий в целях улучшения качества жизни российских граждан. В мероприятии примут участие представители государственных, общественных и коммерческих структур, партнеры из стран Европы и тосударств-участников Евразийского экономического союза.

Тема Конгресса в этом году - роль $n$ потенциал технологий «ЭРА-ГЛОНАСС" в создании нового качества жизни граждан, возможностей для бизнеса и достижении стратегических целей государства,

Деловая программа посвящена перспективам развития системы «ЭРА-ГЛОНАСС», иифровизации транспортной отрасли, вопросам создания единого пространства безопасности на дорогах Евразии, практике внедрения инновационіных успуг, экспорту российских решений.

Oprantoridat

АО глонасс

\section{B paskax}

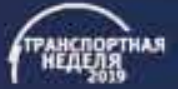

$6+$

Участие в Конгрессе бесплатное по предварительной регистрации.

По вопросам участия и информационного сотрудничества обращайтесь: +7 (495) 766-51-65; +7 (495) 988-47-10; infolacongress-glonass.ru 
среди потенциальных покупателей CD-ROM большинство - состоятельные поклонники классиче ской музыки, а на японском музыкальном рынке абсолютный лидер по продажам Девятая симфония Бетховена. Ее исполнение длится 73,5 мин. Пересчитав 74 мин 16-битного стереозвука на байты, инженеры Sony и установили данный стандарт.

В 1994 году компания вышла на новый рынок видеоигр с невероятно успешной приставкой PlayStation и просто взорвала индустрию. Это была собственная разработка талантливого исследователя Кена Кутараги и его команды. В 1998 году PlayStation 1 принесла компании 5 млрд долл. и 40\% прибыли. Через год на рынок поступает ее модифицированная модель - PlayStation 2 - самая продаваемая консоль в истории всего семейства. К 2000 году приставка стояла уже в каждой четвертой американской семье, а через четыре года их выпуск достиг 100 млн. Сегодня продажи составляют четверть общей выручки корпорации.

Хит-парад новаторских предложений от Sony длился более полувека. Вклад компании в мировую индустрию домашней электроники аксиоматичен. Прежде всего, это уникально-мастерский по классу и находкам переход на полупроводниковую технологию в производстве и совершенствовании теле- и радиоприемников, а следовательно - экономия электроэнергии, высокое качество изображения и звука, ценовая доступность и расширение функциональных возможностей. А также предложения миру: семейства игровых приставок, с широким спектром функциональных возможностей; первой в мире записывающей видеокамеры, позволяющей снимать фильмы не только профессионалам, но и любителям; аудиоплеер. В итоге компания-новатор улучшила качество жизни современников, повысила уровень технической зрелости страны, способствовала росту ее имиджа и экономического потенциала.

Когда в начале 1960-х годов на американские прилавки хлынул поток дешевых и качественных товаров Sony, в стране началась паника по поводу абсолютного ее господства в мировом производстве бытовой электроники. Реакция на hi-tech-победы Sony была предсказуема. В ходе массированной пропагандистской кампании под девизом Be American - buy American (Будь американцем - покупай американское) Д.Кеннеди даже обратился к народу с призывом поддержать отечественную промышленность. Лейбл Made in Japan стал в мире синонимом высочайшего качества, и некоторые американские фирмы даже работали под японцев, выбирая похожие по звучанию названия.
C 1960-х началось победоносное шествие Sony по всему миру: ее дочерние компании открывались в Великобритании, Франции, Германии и других странах. Революционные разработки стали фирмен ным знаком Sony. Как же удалось компании добиться такого успеха?

\section{АЗБУКА МЕНЕДЖМЕНТА ОТ А. МОРИТЫ}

Известный слоган компании "Это не сон, это - Sony!" - точное отражение удивительных успехов команды под началом двух друзей, профессионалов своего дела. Увлечение электроникой было смыслом их жизни. У каждого из них была чет кая специализация. Технический гений Ибука вплотную занимался разработкой новых продуктов. А король менеджмента Морита руководил вопросами управления и сбыта. Однако именно Ибука еще в 1947 году - на старте - предложил устав компании, который состоял из семи клятв-обещаний: "Мы никогда не будем получать доход нечестным путем; мы сосредоточимся на производстве сложных устройств, которые будут приносить пользу обществу; мы не будем делить нашу продукцию на механическую и электронную и сосредоточим наши знания и опыт одновременно в обеих областях; мы предоставим полную независимость предприятиям, которые будут с нами сотрудничать, и будем стремиться укреплять и развивать отношения с ними; мы будем отбирать служащих на основе их способностей и личных качеств; в нашей компании не будет формальных постов; мы будем выплачивать нашим сотрудникам премии, пропорциональные доходам, полученным в результате их деятельно сти, и приложим все усилия, чтобы обеспечить им достойное существование". Позднее Морита изложил идеологию корпорации более изящно в манифесте "Новаторский дух Sony". Он гласил: "Sony - компанияпервопроходец и всегда стремится идти своей дорогой. Прогрессируя, Sony стремится служить человечеству. Она всегда будет исследователем неизвестного. Sony исповедует принцип уважения и поощрения способностей личности и всегда пытается дать чело веку возможность проявить себя наилучшим образом. В этом и есть жизненная сила Sony". В режис суре блестяще выстроенного менеджмента система работала эффективно и без сбоя.

Рабочие практики Мориты актуальны и сегодня. Во-первых, коллектив воспитывался и закалялся на началах чести, совести, преданности и чувства долга перед страной и товарищами. Это соответ ствовало врожденной национальной самоидентичности - обостренным чувствам долга и благодарности как к коллективу, так и работодателю. Система 
пожизненного найма психологически лишь усиливала эти качества. Морита стремился находиться в постоянном контакте с сотрудниками и старался создать им максимально достойные рабочие условия. Во-вторых, в стремлении развеять раз и навсегда бытующее в те времена в мире представление о низкопробности японских товаров, Морита поставил контроль качества во главу угла. Используя принципы управления качеством, предложенныеамериканским профессором Э.Демингом, Sony стала фанатом качества и флагманом надежности. Недаром именно магнитофон Sony был доставлен "Аполлоном-11" на Луну и транслировал музыку на Землю.

Третья рабочая практика - четкая организация системы менеджмента. Для эффективного выполнения задач структура компании делилась на группы (база научных знаний, проектная, бизнес-группа), имеющие свои функции, но тесно взаимодействующие между собой. Четвертая - Sony сломала клеймо "заимствования", присущее азиатским hi-techкомпаниям. Она творила и собственные инновационные продукты, формируя собственную нишу на японском и мировом рынке. Ее вклад в технологию производства и контроль качества тоже был творческим. "Некоторые называли нас "морскими свинками" электронной промышленности. Мы производили новые товары, а промышленные гиганты выжидали, пытаясь определить, будет ли наш товар иметь успех. И если он имел успех, они быстро выпускали на рынок такой же", - вспоминал Морита.

Наконец, в управленческой практике Морита часто жертвовал сиюминутным успехом ради будущей долгосрочной выгоды. Он резко критиковал стремление западных менеджеров служить акционерам, а не клиентам и фирме, мерить эффективность бизнеса дивидендами: "Менеджеры могут демонстрировать прекрасные итоги и в то же время погубить компанию, если не инвестируют будущее. Менеджмент начинается не с итогов в балансовом отчете, которые могут быть сведены сегодня с активным сальдо, а завтра с дефицитом. Доля рынка важнее немедленной прибыли!" Он всегда доверял своей интуиции и творческому мышлению больше, чем маркетинговым исследованиям и отчетам экспертов. Лозунг его команды - "Внимательно наблюдайте за тем, чем и как живут люди, вырабатывайте интуитивное ощущение того, что им нужно, и создавайте это. Не занимайтесь исследованиями рынка". Такое видение и позволило Sony одерживать победы.

\section{ЖИЗНЬ ПОСЛЕ ПАССИОНАРИЕВ}

Скорость инновационного hi-tech-экспресса зашкаливает. Современные реалии требуют умения принимать управленческие решения быстро, смело, агрессивно. Сумасшедшая динамика рынка не оставляет времени на маркетинговые исследования. Опыт и интуиция маркетолога важнее, чем полевая информация.

"Революционный" полет компании пошел на снижение к началу 21 века. Уход харизматичных лидеров не проходит бесследно. Новое руководство, вооруженное дипломами МВА, двинулось по пути роста массы продаж и снижения издержек. А ведь раньше менеджмент компании уделял 85\% своего времени вопросам НИОКР, 10\% - кадрам и лишь оставшиеся 5\% - финансам. Переформатирование политики привело к тому, что старые продукты несколько улучшились, но поток инновационных технологий скоро иссяк. Лидирующие позиции Sony пошатнули также и компании других азиатских стран (Южной Кореи, Тайваня и Китая). С дешевой рабочей силой конкурировать трудно. Sony постепенно стала терять престиж пионерской фирмы! Более того, она стала убыточна.

Путь к возрождению можно датировать 2012 годом, когда у ее руля встал Кадзуо Хираи. Он не был великим визионером, но, безусловно, отличным управленцем, умеющим действовать жестко и упорно ради большой цели. Взяв на себя руко водство Sony в непростые времена, Хираи сумел за четыре года вернуть компании прибыльность, упразднив менее важные подразделения и сосредоточившись на главном и утраченном - инновационном мейнстриме. Политика, анонсирован ная им в рамках программы One Sony, приносит не только дивиденды по сей день, но и служит хорошим "фундаментом" для реинкарнации компании, которую в 2018 году провозгласил его преемник и единомышленник Кениторо Есида. В планах генерального директора вернуть Sony дух инноваций и лидерство на мировом hi-tech-рынке. Он обратился к интеллектуальному ядру компании с призывом творить новые продукты, расширяя их спектр до роботов и автомобилей, а также не только тонко ощущать нынешние потребности рынка, но и предвосхищать будущие и не бояться опередить время. Отцы-основатели учили не повторять одну и ту же ошибку дважды и главное - не опоздать! Компания по-прежнему верна их заветам и свято чтит корпоративный кодекс, на скрижалях которого высечены: честность, справедливость, добросовестность, уважение и ответственность. Поэтому неслучайно в этом году институт Ethisphere признал Sony одной из самых этичных компаний мира. В наш век такая оценка этики ведения бизнеса дорогого стоит. С возвращением, Sony! 


\section{V Международная конференция \\ APKTИKA-2020}

Арктика: шельфовые проекты и устойчивое развитие регионов

\section{9-20 Февраля 2020, Москва}

\section{GaHb участником}

Специализированная выставка | Спонсорство

Тел.: +7 (495) 662-97-49 (многоканальный)

Организаторы:

Электронная почта: arctic@s-kon.ru www.arctic.s-kon.ru

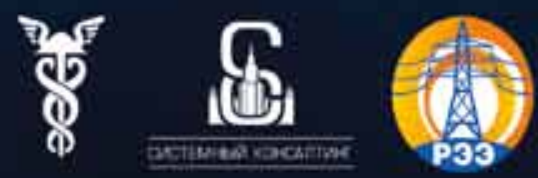


TEXHOCФEPA

РЕКЛАМНО-ИЗДАТЕЛЬСКИЙ ЦЕЕНТР

\section{0\% ГАРАНТИЯ ПОЛУЧЕНИЯ ВСЕХ НОМЕРОВ}

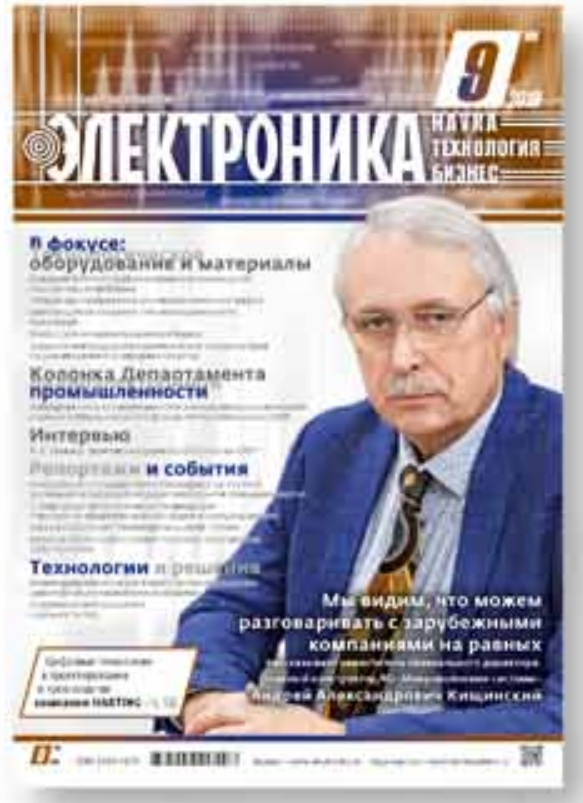

Стоимость 2200 р. за номер

Периодичность: 10 номеров в год

www.electronics.ru

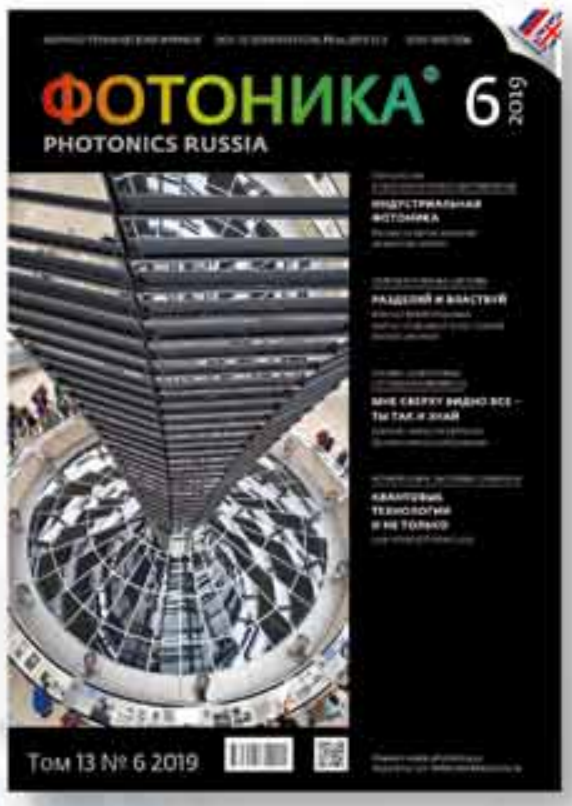

Стоимость 1430 р. за номер

Периодичность; 8 номеров в год

www.photonics.su
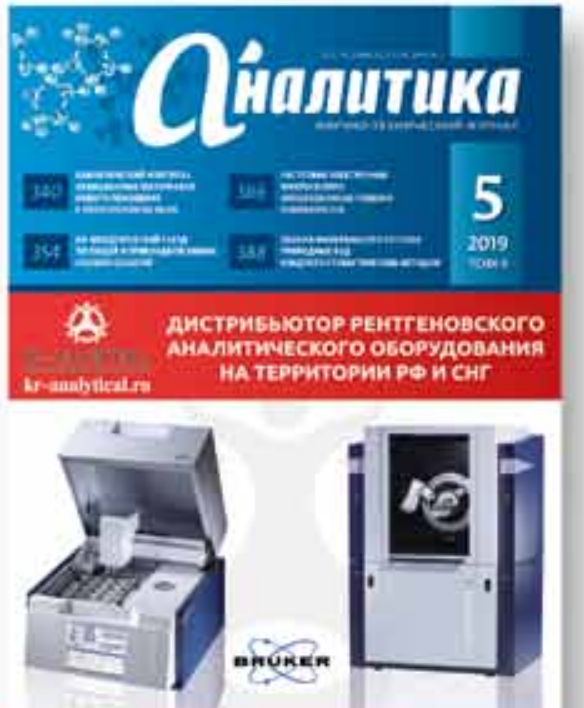

(ii)

미ำำ

Стоимость 1430 р. за номер

Периодичность: 6 номеров в год www.j-analytics.ru

\section{ПОДПКСКА НА ХУРНАЛЫ}

\section{www.technosphera.ru}

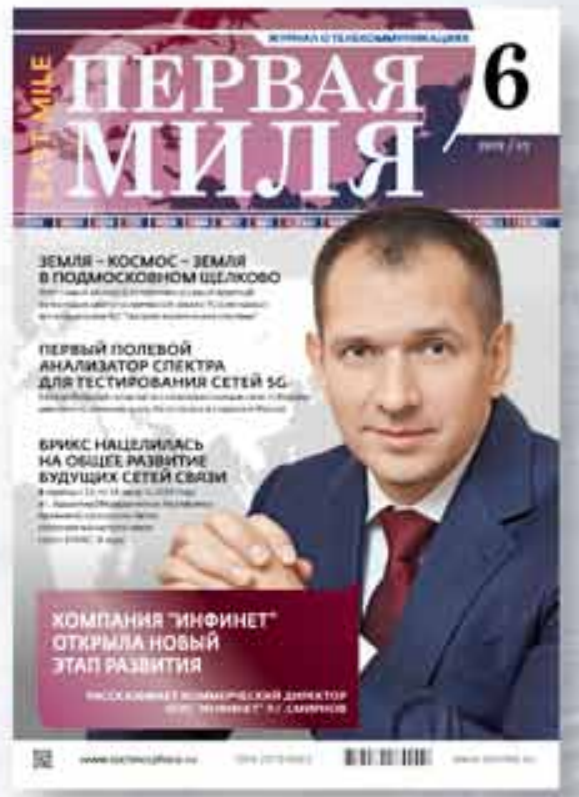

Стоимость $1056 \mathrm{p}$, за номер

Периодичность: 8 номеров в год

www.lastmile.su

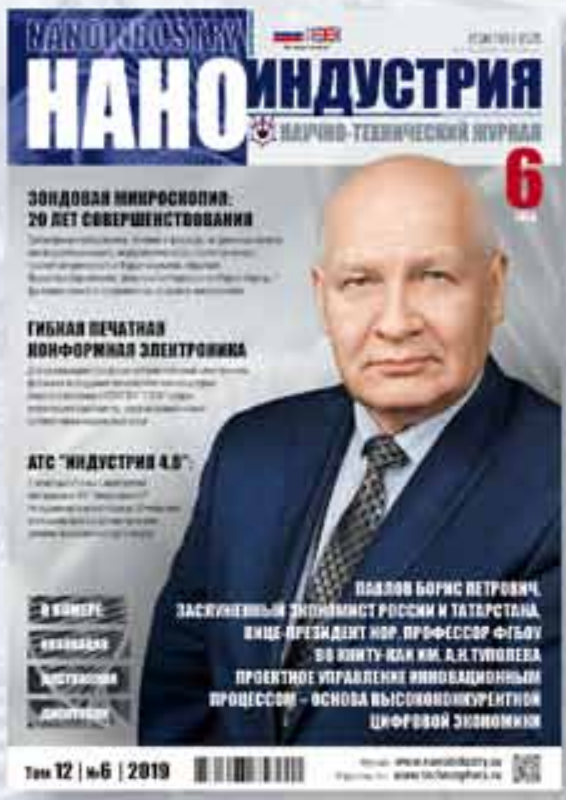

Стоимость 1287 p. за номер

Периодичность: 8 номеров в год

www.nanoindustry.su

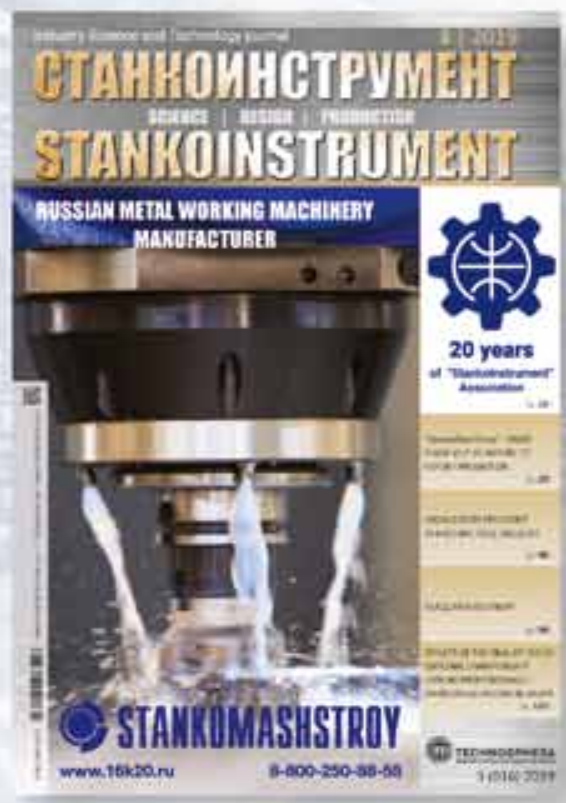

Стоимость 1716 p, за номер

Периодичность: 4 номера в год www.stankoinstrument.su 